\title{
Comparison of Submerged Arc Welding Process Modification Influence on Thermal Strain by in-situ Neutron Diffraction
}

\author{
Rahul Sharma ${ }^{1, a^{*}, \text { Uwe Reisgen }}{ }^{2, b}$ and Michael Hofmann ${ }^{3, c}$ \\ ${ }^{1,2}$ RWTH Aachen University, Welding and Joining Institute, Pontstr. 49, 52062 Aachen, Germany \\ ${ }^{3}$ Heinz-Maier-Leibniz-Zentrum, FRMII, Technical University Munich, Lichtenbergstr. 1, 85747 \\ Garching, Germany \\ a *sharma@isf.rwth-aachen.de, ${ }^{b}$ reisgen@isf.rwth-aachen.de, 'michael.hofmann@frm2.tum.de
}

\begin{abstract}
Keywords: Neutron Diffraction, Strain Analysis, in-situ Experiment, Submerged Arc Welding, Cold Wire
\end{abstract}

\begin{abstract}
In this paper the application of neutron diffraction for measuring the thermal strain field in the vicinity of the weld pool during submerged arc welding is described. The aim of the research was to determine the influence of a welding process modification on the thermal strain within a sample rod. The welding experiment was carried out on the instrument STRESS-SPEC at the MLZ FRMII facility in Garching, Germany. Submerged arc welding equipment with additional cold wire feeding was adapted to the diffractometer and thereon single layer bead-on-plate welds were carried out. Sample rods made of the nickel base alloy 625 were used. The measured strain values are presented and discussed with respect to the resulting weld bead geometry and the thermal profile within the sample.
\end{abstract}

\section{Introduction}

The application of arc welding processes on metallic materials implies high gradients of temperature, strain and stress due to the high power density of the moving heat source. Besides the deterioration of mechanical properties, the buildup of residual stresses follows up the thermal manufacturing processes (Figure 1 left). For the estimation of residual stresses within welded components, it is therefore inevitable to know the transient temperature- and strain fields in the weld zone. Furthermore thermomechanical models for the description of the materials behavior are needed to understand the development of stress and distortion.

The description of thermomechanical behavior of materials subject to welding relies on continuum mechanics principles which are well established. Nevertheless it is still difficult to estimate the resulting distortion and residual stress in welded structures due to the complex superposition of influencing factors. Experimental investigations to analyze the stress and strain during welding have been conducted in the past to achieve a deeper knowledge of the physical processes leading to buildup of residual stresses. These experiments relied on various surface strain measurement principles as strain gauges on the base metal surface, e.g. [1] or Digital Image Correlation [2]. Another approach is the application of neutron diffraction for the determination of the in-depth-strain state. A first experiment using TIG remelting of a 316L sample has been described in [3] and [4], which showed the feasibility of using a quasi-stationary welding setup.

A central issue in welding of high alloyed steels and nickel based alloys is the formation of hot cracks. These welding defects occur if a critical combination of chemical composition, mechanical load and welding parameters are used. Therefore it is difficult in high performance welding processes to hit the suitable parameter window. The submerged arc welding process (SAW) is such a high performance welding process and it is often applied for manufacturing of thick walled components because of its high deposition rate, deep penetration and process stability. In some nickel base alloys it is difficult to set up even a SAW process with sufficiently low heat input to prevent hot crack formation. Furthermore the loss of alloying elements through burn-off to the slag limits the feasibility of SAW for creep resistant nickel based alloys. 
To overcome these restrictions the submerged arc welding with cold wire addition (SAW-CW) process has been investigated in the past [5-7]. Slight evidence for lower hot crack formation when using SAW-CW led to the conduction of a in-situ-diffraction experiment to compare the process
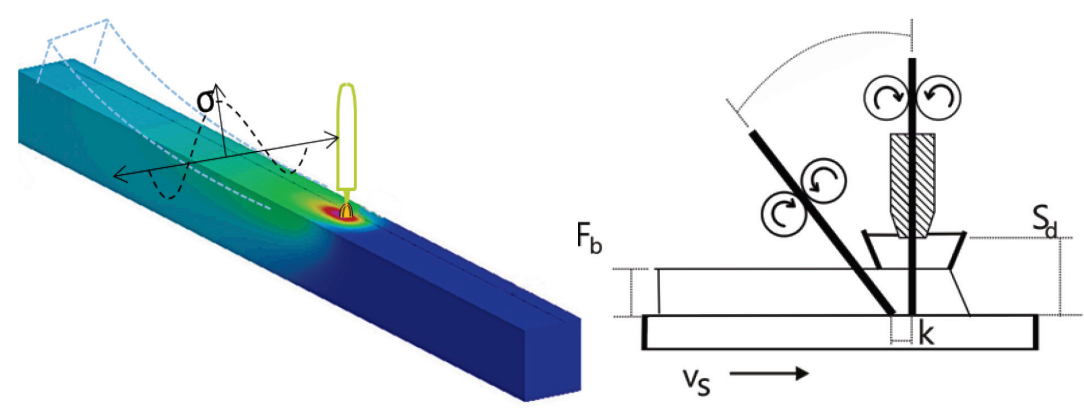
induced elastic strains in the hot surrounding zone of the weld pool.

Figure 1: colour mapped temperature distribution in a welded sample rod (left), basic principle of $S A W-C W$ process with parameters $\mathrm{Fb}$ (flux height), $S d$ (contact tip distance), $k$ (cold wire distance) (right)

\section{Experimental Approach}

The common SAW process is carried out using a continuously fed wire electrode. By applying the welding voltage between the contact piece and the base metal, an electric arc burns under the welding flux which is melted to form the slag pool. Metal vapour and gasified slag components form the cavity wherein the electric arc burns and the metal droplet transfer takes place.

The SAW-CW process complements an additional welding wire, which is fed into the weld pool behind the welding electrode. Since there is no voltage applied between additional wire and base metal, the melting is exclusively induced by the excessive heat of the weld pool. In this arrangement the loss of alloying elements is reduced as the droplet does not pass the arc zone. The electrical process characteristics are not influenced by the cold wire feeding, so that no change in heat input occurs.

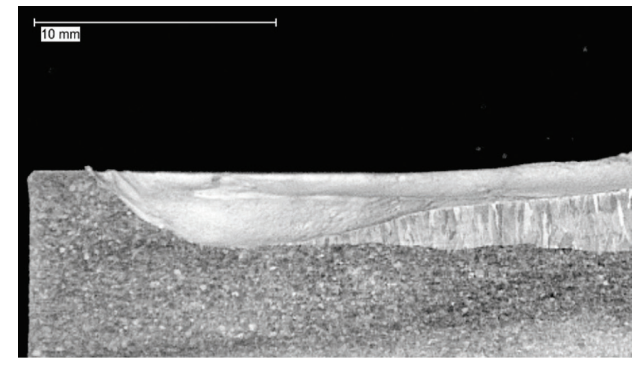

SAW

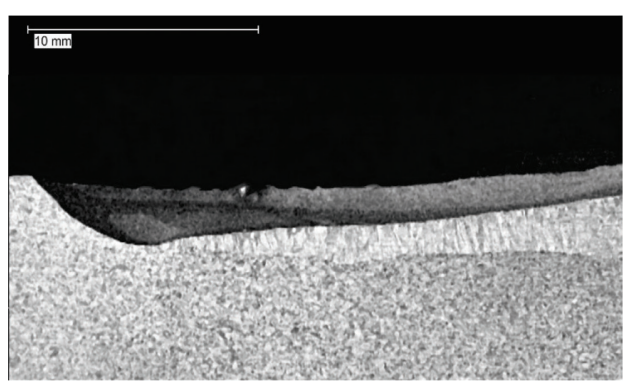

SAW-CW
Figure 2:

longitudinal centerline section of a $S A W$ weld bead (left) and a $S A W$ $C W$ weld bead with a cold wire speed of $50 \%$ oft he electrode feed speed

A change of weld pool geometry and thermal field is the result of the additional wire feeding. The weld bead buildup increases with additional wire feeding whereas the penetration depth is reduced [5].

The SAW-CW leads to reduced peak temperatures near to the fusion line, but the overall cooling time of the weld metal is mostly uninfluenced [6,8]. This could be caused by the reduced heat dissipation area between the weld pool and the base metal, which is a result of the weld pool migration out of the base metal.

In this study a high temperature nickel base alloy 625 has been used for the experiments. It consists of a fully austenitic microstructure with solid solution hardened matrix. The composition is given in Table 1.

Table 1: chemical composition of Alloy 625 base metal rods (measured by spark OES)

\begin{tabular}{|c|c|c|c|c|c|c|c|c|c|c|c|c|c|c|}
\hline [\%] & $\mathbf{C}$ & $\mathbf{S i}$ & $\mathbf{M n}$ & $\mathbf{P}$ & $\mathbf{S}$ & $\mathbf{C r}$ & $\mathbf{M o}$ & $\mathbf{F e}$ & $\mathbf{A l}$ & $\mathbf{N b}$ & $\mathbf{T i}$ & $\mathbf{C o}$ & $\mathbf{T a}$ & $\mathbf{N i}$ \\
\hline Base metal & 0,027 & 0,12 & 0,17 & 0,010 & 0,002 & 22,3 & 9,1 & 4,0 & 0,14 & 3,4 & 0,15 & 0,2 & 0,01 & bal. \\
\hline
\end{tabular}

The welding setup was installed on the sample table of the materials diffractometer STRESS-SPEC at the FRMII neutron source in Garching, Germany (Figure 3). Due to the high flux of thermal neutrons 
and the resolution of the area detector, this instrument is intended for such experiments. The basic parameters and performance characteristics have been described elsewhere [9].
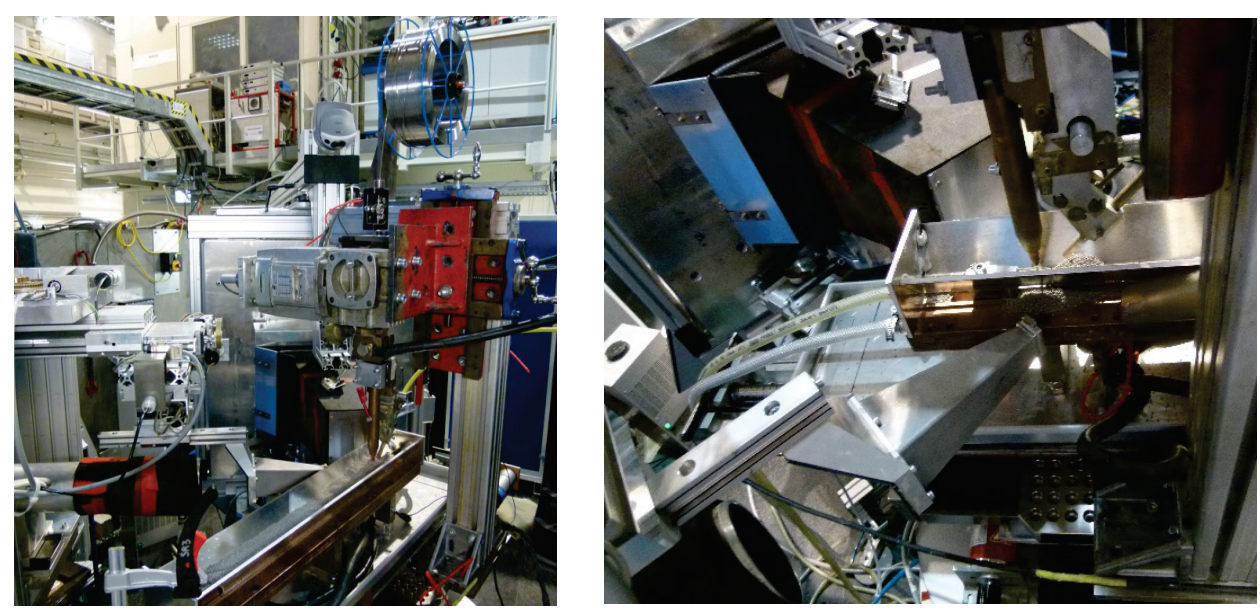

\begin{abstract}
Figure 3: installed welding setup at STRESS-SPEC instrument (left), alignment of beam guidance, detector, welding head and sample table (right)
\end{abstract}

For the in-situdiffraction experiment steady state boundary conditions were needed as the attentuation of the neutron beam while passing through the sample volume led to a minimum time of 30 seconds to achieve an evaluable diffraction peak. This was done by installing the sample rod of the dimensions $20 \mathrm{x}$ $20 \times 500 \mathrm{~mm}^{3}$ on a linear sample table. The position of the welding head was chosen so that the position of diffraction gauge volume with regard to the electrode tip stayed constant. After completion of a runon stage the gauge volume stayed along the same isothermal line for the whole data acquisition time. This arrangement implies that for every measuring point and spatial orientation, a whole sample rod had to be welded.

Table 2: welding parameters used within the experiment

\begin{tabular}{|c|c|c|c|c|c|c|}
\hline & $\begin{array}{c}\text { Heat input } \\
{[\mathbf{k J} / \mathbf{c m}]}\end{array}$ & $\begin{array}{c}\text { Voltage } \\
{[\mathbf{V}]}\end{array}$ & $\begin{array}{c}\text { Current } \\
{[\mathbf{A}]}\end{array}$ & $\begin{array}{c}\text { welding speed } \\
{[\mathbf{c m} / \mathbf{m i n}]}\end{array}$ & $\begin{array}{c}\text { welding wire speed } \\
{[\mathbf{m} / \mathbf{m i n}]}\end{array}$ & $\begin{array}{c}\text { cold wire speed } \\
{[\mathbf{m} / \mathbf{m i n}]}\end{array}$ \\
\hline SAW & 10,5 & 34,6 & 325 & 60 & 6 & 0 \\
\hline SAW-CW & 10,5 & 34,6 & 323 & 60 & 6 & 1,5 \\
\hline
\end{tabular}

To compare the influence of the welding process on the strain field two welding parameter sets were defined (Table 2). The only difference was the cold wire addition in the second set, while all other welding parameters stayed constant.

For both the electrode wire and the cold wire, a commercial welding wire S NI 6625 (ISO 18274) with a diameter of $1.6 \mathrm{~mm}$ was used. The welding flux was SA-AB 2 ( ISO 14174).

For every measuring point the strain in longitudinal direction (parallel to welding direction) and transverse direction were measured. Since the high thermal gradient within the gauge volume of $3 \times 3 \times$ $2 \mathrm{~mm}^{3}$ was suspected to cause extreme peak broadening, every measurement was repeated three times, which sums up to six samples per measuring point.

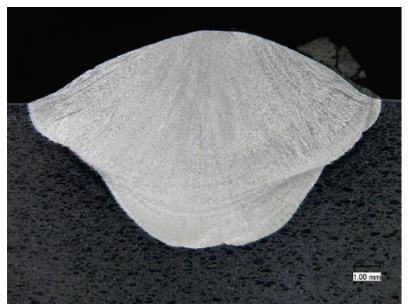

SAW

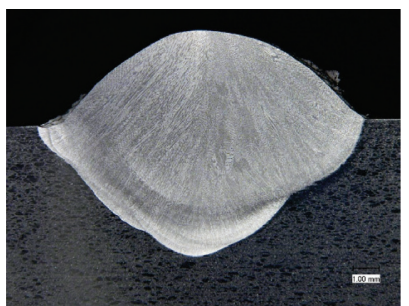

SAW-CW

Figure 4: cross section of SAW (left) and SAW$\mathrm{CW}$ (right) weld beads on Alloy 625 sample rods, welding parameters acc. to Table 2

For the determination of the measuring point location, weld width and penetration depth were determined in preliminary welding experiments using the same welding parameters and materials. It was found that only a slight reduction in penetration depth was achieved when cold wire was fed into the weld pool with $25 \%$ of the electrode speed (Figure 4). Since the SAW process comprises a flux covered welding zone, the length of the weld pool can only be determined by removing the weld pool. 


\begin{tabular}{|c|c|c|}
\hline & $\begin{array}{c}\text { weld pool } \\
\text { length }[\mathbf{m m}]\end{array}$ & $\begin{array}{c}\text { std deviation } \\
(\mathbf{n}=\mathbf{5})\end{array}$ \\
\hline SAW & 69,0 & 0,3 \\
\hline SAW-CW & 67,2 & 0,8 \\
\hline
\end{tabular}

Table 3: weld pool length of SAW and SAW-CW on used Alloy 625 sample rods, welding parameters acc. to Table 2

One possible method consists of blowing out the liquid metal with a high pressure gas stream, while the welding process is shut down [10]. The results are given in Table 3.

Four gauge volume locations (MP1-MP4) were selected taking into account the position of the fusion line (Figure 5).

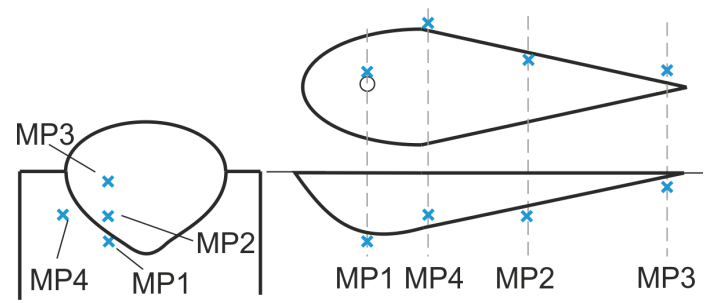

\section{Figure 5: schematic overview of the gauge volume} locations

\section{Results}

For both welding parameter sets, the chemical analysis of the weld metal is given in Table 4.

A slight increase of chromium and molybdenum content in the weld metal could be observed due to the lower burn-off in SAW-CW. The lower iron content however is a result of the lower dilution compared to the SAW process. Due to the relatively low cold wire addition, there is no substantial difference in chemical composition between both variants. Table 4: chemical composition of the weld metal (measured by spark OES)

\begin{tabular}{|c|c|c|c|c|c|c|c|c|c|c|c|c|c|c|}
\hline & $\mathbf{C}$ & $\mathbf{S i}$ & $\mathbf{M n}$ & $\mathbf{P}$ & $\mathbf{S}$ & $\mathbf{C r}$ & $\mathbf{M o}$ & $\mathbf{F e}$ & $\mathbf{A l}$ & $\mathbf{N b}$ & $\mathbf{T i}$ & $\mathbf{C o}$ & $\mathbf{T a}$ & $\mathbf{~ N i}$ \\
\hline SAW & 0,011 & 0,20 & 0,10 & $\begin{array}{c}<0,000 \\
2\end{array}$ & $\begin{array}{c}<0,000 \\
3\end{array}$ & 20,5 & 8,3 & 3,1 & 0,14 & 3,2 & 0,18 & 0,05 & $<0,005$ & bal. \\
\hline $\begin{array}{c}\text { SAW- } \\
\text { CW }\end{array}$ & 0,012 & 0,19 & 0,09 & $\begin{array}{c}<0,000 \\
2\end{array}$ & $\begin{array}{c}<0,000 \\
3\end{array}$ & 20,8 & 8,5 & 2,4 & 0,13 & 3,2 & 0,18 & 0,04 & $<0,005$ & bal. \\
\hline
\end{tabular}

The temperature measurement was carried out using type $\mathrm{K}$ thermocouple wires, which were welded on the ground of cylindrical holes inside the sample rods. The hole depth corresponded to the position of the gauge volume. Since the geometrical extent of the gauge volume led to thermal gradients of several $100 \mathrm{~K}$, the measured values could only be processed as calibration data for a numerical model of the temperature distribution within the sample. Therefore the software simufact.welding has been used. However the temperature to consider is the spatial integration over the gauge volume, since the low thermal conductivity of Alloy 625 leads to steep thermal gradients (Figure 6).

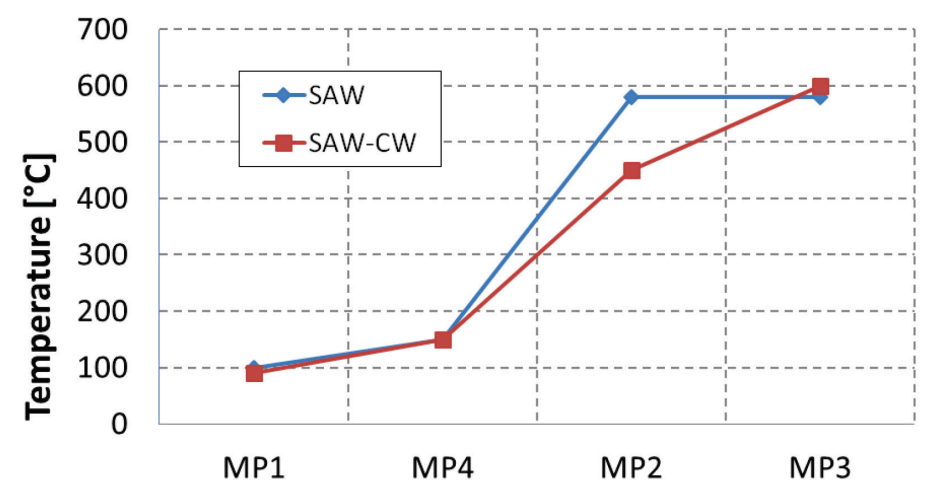

Figure 6: simulated steady state temperature integrated over the gauge volume

The neutron experiment was carried out using a constant wavelength of $1.55 \AA$ which was achieved through the application of a $\mathrm{Si}(400)$ monochromator. For the measurement of strain by neutron diffraction at steady state sources, the 311 peak seems to be the most eligible, since it is least affected to integranular stresses [11]. The average value of lattice plane distance for the 311 peak is shown in Figure 7. However these results show the combined influence of thermal expansion and load or restraint induced elastic strain. A methodology to separate thermal strains and load strains was applied by performing a furnace experiment on the same diffractometer. Therefore a cylindrical sample $(\mathrm{d}=6 \mathrm{~mm})$ was mounted within the diffraction furnace and heated stepwise up to $1200{ }^{\circ} \mathrm{C}$. During every temperature step of $25^{\circ} \mathrm{C}$ a diffraction pattern was acquired. The strains were calculated from the diffraction data, using Eq 1, where $\mathrm{d}$ refers to the actual lattice plane distance, $\mathrm{d} 0$ to the load-free and homogenous tempered lattice plane distance for the respective temperature. 


$$
\varepsilon=\frac{d-d_{0}}{d_{0}}=\frac{\sin \theta_{0}}{\sin \theta}-1 .
$$

The calculated strain values are given in Figure 8. For the SAW strain in longitudinal direction it can be seen that there is a zone of tensile strain behind the welding electrode (MP4). With increasing distance to the electrode, the tensile strain relaxates to nearly zero. For the SAW-CW process, the tensile strain in longitudinal direction is significantly lower. Furthermore compressive strain is the leading influence afterwards. In transverse direction the strain distribution appears to be different. The SAW$\mathrm{CW}$ process induces high tensile strain behind the solified weld pool in here. This could be caused by a geometrical effect which is due to the small width of the sample. Since the weld penetration area and the peak temperatures in SAW are higher compared to SAW-CW, a larger proportion of the total width of the sample is subject to softening. The lower dilution and higher weld buildup in SAW-CW will result in a higher restraint intensity. Furthermore the zone of deep penetration of the weld pool is much smaller in SAW-CW. For moving heat sources a compressive plastic zone is found near to the weld pool before the peak temperature is reached. After the peak temperature has been reached the strain state changes to plastic tensile strain [12]. When considering Figure 8 this is reflected by both welding processes. Even though the integral temperature of the gauge volume is lower at position MP4, the formation of hot cracks will originate from this position on near to the fusion line. Since the longitudinal strain is compressive for SAW-CW a lower risk of hot crack formation is suspected. For wider samples, the transverse tensile strain for SAW-CW is expected to become compressive, as stated before. This has to be proved within further investigations.

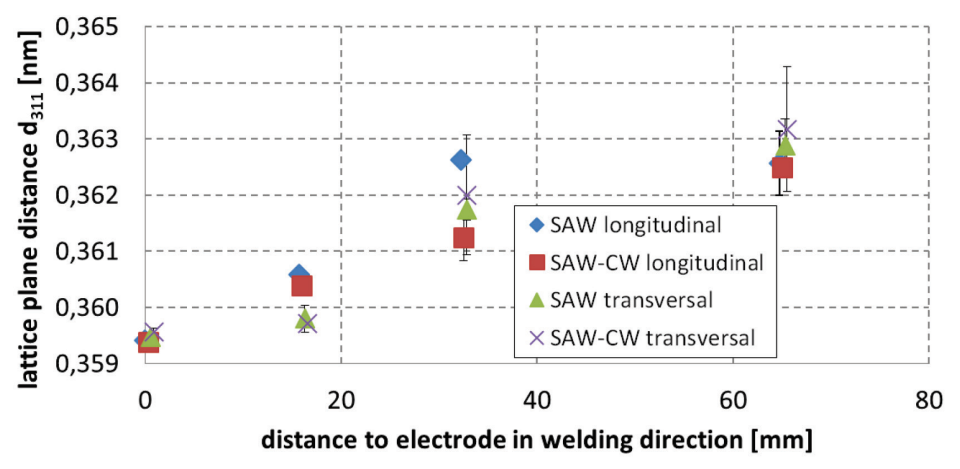

Figure 7: average lattice plane distance in welded samples, gange volume position axis parallel to welding direction

\section{Conclusion}

The measured strain field during welding with both processes shows a direct relationship to geometrical and thermal influencing factors. It complies with fundamental descriptions of stress and strain in the zone around the weld pool [12]. Based on the experimental results a slightly lower portion of tensile strain in the deep penetration area of the weld pool could be observed but it is still unclear if there is a direct relationship to the formation of a lower hot cracking risk.

However this reflects the limitation of the method stemming from the necessary use of relatively large gauge volume. To overcome this restriction in future experiments, the use of synchrotron radiation for in-situ strain measurement will be taken into account. A transient measurement of strain at the fusion line could give clearer results.

\section{Summary}

Within this work, neutron diffraction measurements during welding have been carried out to compare the influence of SAW and SAW-CW on the resulting strain field in the base metal near to the fusion line. For the considered nickel base alloy 625 it was shown that the strain field in longitudinal direction has a higher tensile proportion for SAW. The higher tensile strain in transverse direction was put down to the restraint condition and sample geometry in SAW-CW. For future work a smaller gauge volume is needed to enhance the current results.

\section{Acknowledgement}

All presented investigations were conducted in the context of the Collaborative Research Centre SFB1120 "Precision Melt Engineering" at RWTH Aachen University and funded by the German Research Foundation (DFG). For the sponsorship we wish to express our sincere gratitude. This work is 
based upon experiments performed at STRESS-SPEC instrument operated by HZG, FRMII and TU Clausthal at the Heinz Maier-Leibnitz Zentrum (MLZ), Garching, Germany.

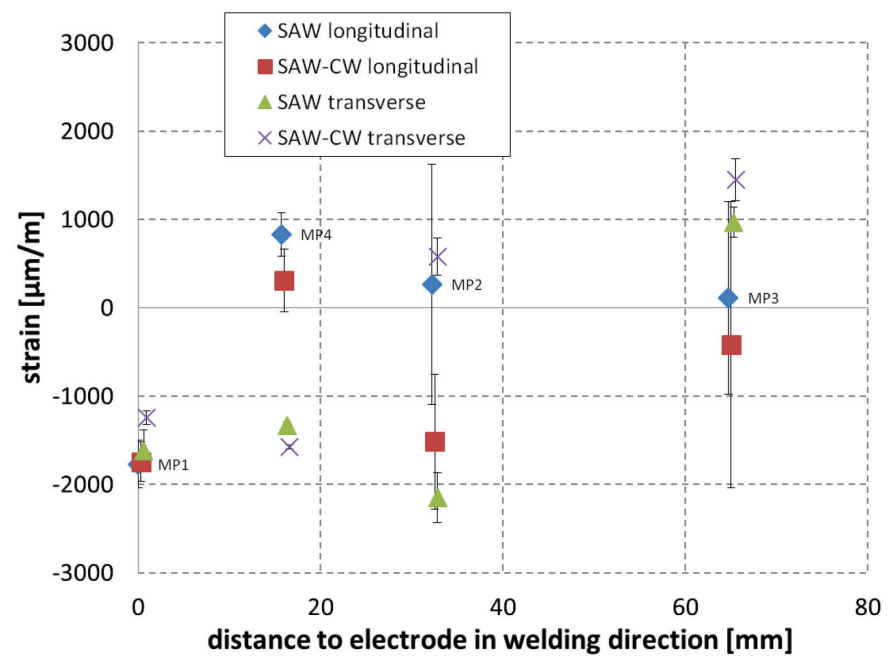

Figure 8: average strain in welded samples, gauge volume position axis parallel to welding direction

\section{References}

[1] W. Dahl, U. Dilthey in D. Aurich, K.H. Kloos (Eds.):"Eigenspannungen und Verzug durch Wärmewirkung“, S. 175-201, Wiley-VCH Weinheim, 1999

[2] M. Shibahara, K. Ikushima and S. Itoh STWJ 2012 Vol 17 No 6 pp. 511-517 doi 10.1179/1362171812Y.0000000027

[3] U. Reisgen, C. Geffers, R. Sharma, J. v. d. Heydt, MSF Vols. 768-769 (2014) pp 644-651, doi:10.4028/www.scientific.net/MSF.768-769.644.

http://dx.doi.org/10.4028/www.scientific.net/MSF.768-769.644

[4] U. Reisgen, R. Sharma, J. v. d. Heydt, AMR Vol. 996 (2014) pp 424-430, doi:10.4028/www.scientific.net/AMR.996.424.

http://dx.doi.org/10.4028/www.scientific.net/AMR.996.424

[5] U. Reisgen, U. Dilthey, I. Aretov, . in T. Böllinghaus, H. Herold, C. E. Cross, J. C. Lippold (Eds.): Hot Cracking Phenomena in Welds, Pt. 2. Berlin, Heidelberg, Springer, 2008 pp. 215- 240

[6] U. Reisgen, K. Willms, S. Jochindke, IIW-DOC: XII-2207-15, 2015

[7] R. Sharma, IIW-Doc II-1847-13 (II-C-458-13), 2013

[8] L. Karlsson, H. Arcini, P Dyberg, S. Rigdal, M. Thuvander, Proc. Stainless Steel World Conference Maastricht, NL, 2003, pp. 283-294

[9] Heinz Maier-Leibnitz Zentrum. STRESS-SPEC: Materials science diffractometer. Journal of largescale research facilities, 1, A6., 2015, http://dx.doi.org/10.17815/jlsrf-1-25.

[10] U. Reisgen, A. Schiebahn, O. Mokrov, O. Lisnyi, R. Sharma, CWA Journal 11, 2015, 6, pp. 90 - 94

[11] M.R. Daymond, B. Clausen, Journal of Applied Physics 82, No. 4, pp. 1554 - 1562, 1997 http://dx.doi.org/10.1063/1.365956.

[12] Radaj, D.: Heat effects of welding, Springer Berlin, 1992. http://dx.doi.org/10.1007/978-3-64248640-1 